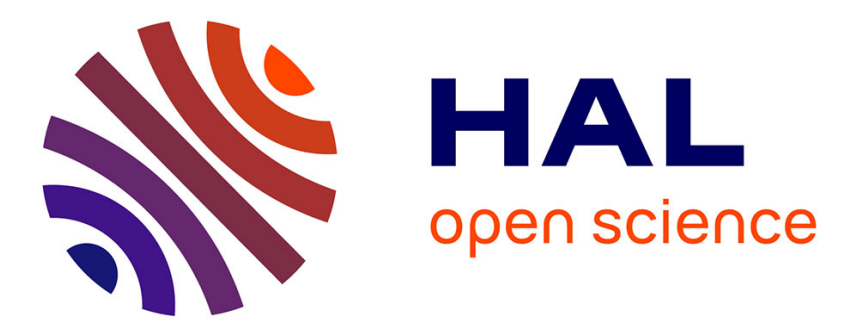

\title{
The effect of nanostructures on high pressure intrusion-extrusion of water and electrolyte solutions in hierarchical nanoboxes of silicalite-1
}

Joffrey Huve, T. Jean Daou, Habiba Nouali, Joël Patarin, Andrey Ryzhikov

\section{- To cite this version:}

Joffrey Huve, T. Jean Daou, Habiba Nouali, Joël Patarin, Andrey Ryzhikov. The effect of nanostructures on high pressure intrusion-extrusion of water and electrolyte solutions in hierarchical nanoboxes of silicalite-1. New Journal of Chemistry, In press, 10.1039/C9NJ01891C . hal-02413840

\section{HAL Id: hal-02413840 \\ https://hal.science/hal-02413840}

Submitted on 19 Jan 2022

HAL is a multi-disciplinary open access archive for the deposit and dissemination of scientific research documents, whether they are published or not. The documents may come from teaching and research institutions in France or abroad, or from public or private research centers.
L'archive ouverte pluridisciplinaire HAL, est destinée au dépôt et à la diffusion de documents scientifiques de niveau recherche, publiés ou non, émanant des établissements d'enseignement et de recherche français ou étrangers, des laboratoires publics ou privés. 


\title{
The effect of nanostructures on high pressure intrusion-extrusion of water and electrolyte solutions in hierarchical nanoboxes of silicalite-1
}

\author{
Joffrey Huve, ${ }^{a b}$ T. Jean Daou, (D)*ab Habiba Nouali, ${ }^{a b}$ Joël Patarin $^{a b}$ and \\ Andrey Ryzhikov (D) *ab
}

\begin{abstract}
This study of high pressure intrusion-extrusion of water and $20 \mathrm{M} \mathrm{LiCl}$ solution in silicalite-1 nanoboxes demonstrates how nanostructures can determine the properties of materials. The drastic effect of the presence of cavities on the intrusion-extrusion behavior and characteristics has been observed, particularly, in the case of $\mathrm{LiCl}$ aqueous solution. The nanoboxes demonstrate a combination of bumper and spring behavior in the first intrusion-extrusion cycle. The intrusion of $20 \mathrm{M} \mathrm{LiCl}$ solution is only partially reversible and takes place in two clearly marked steps, whereas only one intrusion step with a fully reversible spring behavior is observed for the micro- and nanocrystals. The first step, with an intruded volume of $0.07 \mathrm{~mL} \mathrm{~g}^{-1}$ and an intruded pressure of $98 \mathrm{MPa}$, is irreversible and corresponds probably to the filling of mesoporous cavities, and the second one, with an intruded volume of $0.08 \mathrm{~mL} \mathrm{~g}^{-1}$ and an intrusion pressure of $273 \mathrm{MPa}$ is fully reversible and related to the filling of the micropores of silicalite- 1 walls. The filling of the nanocavities occurs probably through small mesoporous cracks in the nanobox walls. The characterization by structural and physicochemical methods shows that the dissolution-recrystallization process leads to the formation of a MFI structure with lower content of silanol defects in comparison with initial nanocrystals explaining the steeper slope of the intrusion step and the higher intrusion pressure observed for the "nanobox- $\mathrm{H}_{2} \mathrm{O}$ " and "nanobox-20 M LiCl" systems.
\end{abstract}

\section{Introduction}

High pressure intrusion-extrusion of nonwetting liquids into porous solids is a promising technology for mechanical energy absorption and storage. ${ }^{1,2}$ This principle of energy absorption proposed by V. Eroshenko is based on the conversion of the applied mechanical energy into the energy of solid-liquid interfaces by forced penetration (intrusion) of a nonwetting liquid into the pores of materials, where the liquid is transformed into a multitude of molecular clusters. ${ }^{3}$ The absorption energy value is determined by the volume of intruded liquid and the intrusion pressure according to the formula: $W=\int_{V 1}^{V 2} P \mathrm{~d} V$, where $P$ is the intrusion pressure and $V 1$ and $V 2$ are the volumes of the system before and after intrusion. The first systems "nonwetting liquid-porous solid", also called Heterogeneous Lyophobic Systems (HLS), were based on water and grafted porous silica. ${ }^{4,5}$ Since 2001 , pure-silica zeolites (zeosils) having hydrophobic properties have been used as porous matrixes for HLS. ${ }^{6}$ Depending on the zeosil structure (pore openings, cages or channel systems, framework stability, the presence of hydrophilic defects etc.) and the nature of the nonwetting liquid, zeosil-based HLS can absorb, dissipate or restore the supplied mechanical energy with a more or less significant hysteresis that corresponds to a bumper, shockabsorber or spring behavior, respectively. ${ }^{6-17}$ Due to the subnanometer size of pore openings, the zeosils demonstrate high values of intrusion pressure - up to $180 \mathrm{MPa}$ for water ${ }^{10}$ and $357 \mathrm{MPa}$ for electrolyte aqueous solutions ${ }^{17}$ - that allows achieving a stored energy value of up to $15 \mathrm{~J} \mathrm{~g}^{-1}$ for water and $91 \mathrm{~J} \mathrm{~g}^{-1}$ for the solutions. However, in comparison with hydrophobic Zeolitic Imidazolate Frameworks ${ }^{18-22}$ and mesoporous silica ${ }^{23-28}$ with the intruded volume of up to $0.5 \mathrm{~mL} \mathrm{~g}^{-1}$, that of zeosils is relatively low - from 0.03 to $0.23 \mathrm{~mL} \mathrm{~g}^{-17,9,14,29}$ which is directly related to the pore volume determined by the structure. Thus, a potential solution to improve the energetic performance of zeosil-based HLS is an increase of pore volume by creating nanostructured hierarchical porous materials with additional micro-, meso- and macropores. A wide spectrum of hierarchical zeolites is extensively studied for applications in adsorption and heterogeneous catalysis. ${ }^{30-33}$ The first research on hierarchical materials for energetic applications was realized 
by Trzpit et al. on hydrophobic silicalite-1 (MFI-type zeosil) sample, where additional micro-, meso- and macropores were created by using a carbon black porogen and surfactant template. ${ }^{34,35}$ However, the increase of intruded volume and stored energy was quite low which can be related to the fact that the meso- and macropores were opened to the liquid and thus filled at relatively low pressure because of their high diameter. The creation of mesopores isolated from the liquid by hydrophobic zeolitic micropore walls, which the nonwetting liquid should traverse, could be a possible manner to avoid such low pressure filling. A potentially interesting structure for energetic applications is pure silica MFI-type zeolite (silicalite-1) hollow nanoboxes. Tuel et al. obtained these nanoboxes, intended for catalytic applications, by dissolution-recrystallization of silicalite- 1 nanocrystals. ${ }^{36-39}$ When the dissolution process is performed in the presence of structure-directing molecules, here an alkali-free tetrapropylammonium hydroxide (TPAOH) solution, and under appropriate conditions, the highly defective core of the silicalite-1 crystal is preferentially dissolved. The recrystallization of the dissolved silica species can only occur on the outer surface in the presence of $\mathrm{TPA}^{+}$cations, which are too large to enter the zeolite pores. In this work we present a study on water and electrolyte aqueous solution intrusion-extrusion in the silicalite-1 nanoboxes for energetic applications. The results are compared to the ones obtained for the initial nanocrystals before TPAOH treatment and for silicalite-1 microcrystals in order to show the influence of nanostructures on the energetic performance.

\section{Results and discussion}

\section{Intrusion-extrusion experiments}

The intrusion-extrusion curves ( $\mathrm{P}-\mathrm{V}$ diagrams) for silicalite- 1 nanoboxes, initial nanocrystals before TPAOH treatment, and the ones obtained for silicalite- 1 microcrystals prepared in fluoride medium from the work of Khay et al. ${ }^{40}$ with water and $20 \mathrm{LiCl}$ aqueous solution are shown in Fig. 1. The corresponding data are reported in Table 1. The volume variation observed at low pressure ( $<1 \mathrm{MPa})$ corresponding to the compression and

the liquid filling in the interparticular porosity of the samples is not shown. The curves are shifted along the $Y$-axis for better visibility. Only the 1 st and 2 nd intrusion-extrusion cycles are shown for "nanocrystal-water" and nanobox-based systems, since the 2nd and 3rd cycles are superimposable. In the case of "nanocrystal-20 M LiCl solution" and microcrystal-based systems only the 1st cycle is shown, since all the cycles are superimposable. A considerable difference in energetic performance is observed between the intrusion-extrusion curves of silicalite-1 microcrystals, nanocrystals and nanoboxes. In comparison with the microcrystals,$^{40}$ the intrusion of water in the nanocrystals occurs at considerably lower pressure (57 against $96 \mathrm{MPa}$ ) and the intruded volume is also much lower ( 0.05 and $0.10 \mathrm{~mL} \mathrm{~g}^{-1}$, respectively). Moreover, the intrusion in the nanocrystals is slightly irreversible in the first cycle, and the intruded volume decreases to $0.045 \mathrm{~mL} \mathrm{~g}^{-1}$ in the following cycles. Such differences can be explained by a high content of hydrophilic

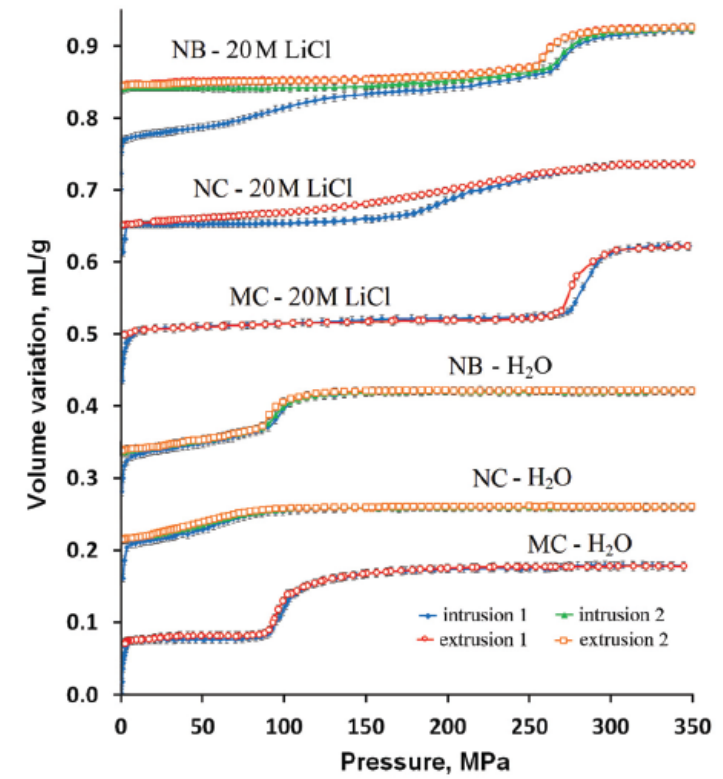

Fig. 1 Intrusion-extrusion curves of the silicalite-1 nanoboxes (NBs), nanocrystals (NCs) and microcrystals (MCs) with water and $20 \mathrm{M} \mathrm{LiCl}$ aqueous solution. The curves are shifted along the $Y$-axis for better visibility. The results for silicalite-1 microcrystals are taken from ref. 40

silanol defects in the nanocrystals obtained in $\mathrm{OH}^{-}$medium, that is confirmed by the characterization results (see TG and NMR sections below), whereas the microcrystals obtained in fluoride medium contain a lower number of silanol groups. ${ }^{40} \mathrm{It}$ is well known that the synthesis in hydroxide medium favours the presence of silanol defects in the silicalite- 1 framework, ${ }^{6}$ but these nanocrystals seem to contain a higher defect content in comparison with those obtained previously. ${ }^{41}$ The lower intruded volume can be explained by the spontaneous filling of a part of pores at a pressure below $1 \mathrm{MPa}$ due to the higher number of silanol groups and consequently the hydrophilic character of these

nanocrystals.

In spite of being obtained in $\mathrm{OH}^{-}$medium from the nanocrystals, the silicalite-1 nanoboxes demonstrate intrusionextrusion curves very different from those of nanocrystals and quite similar to those of silicalite- 1 microcrystals. ${ }^{40}$ Indeed, the "silicalite-1 nanobox- $\mathrm{H}_{2} \mathrm{O}$ " system shows the same spring behavior with a fully reversible intrusion and the same intrusion pressure of $96 \mathrm{MPa}$. Thus, the intrusion corresponds probably to the filling of the microporous walls, whereas the effect of nanocavities is not clearly observed. It is probable that the nanocavities are filled at very low pressure through the mesoporous cracks in the walls of nanoboxes. It is known that such cracks can be present in the walls of zeolite nanoboxes. ${ }^{42,43}$

However, some differences between the nanoboxes and the microcrystals are observed. In the case of silicalite-1 nanoboxes, the intrusion proceeds gradually from the starting pressure to $90 \mathrm{MPa}$, then a marked intrusion step is observed in the range 
Table 1 Characteristics of intrusion-extrusion of water and $20 \mathrm{M} \mathrm{LiClaqueous} \mathrm{solution} \mathrm{in} \mathrm{silicalite-1} \mathrm{nanoboxes} \mathrm{(NBs)} \mathrm{and} \mathrm{manocrystals} \mathrm{(NCs)} \mathrm{compared}$ to the results on silicalite-1 microcrystals (MCs) from ref. 40

\begin{tabular}{|c|c|c|c|c|c|c|c|}
\hline System & $P_{\text {int }}{ }^{a}[\mathrm{MPa}]$ & $V_{\mathrm{inx}}{ }^{a}\left[\mathrm{~mL} \mathrm{~g}^{-1}\right]$ & $P_{\mathrm{ec}}{ }^{a}[\mathrm{MPa}]$ & $V_{\operatorname{ext}^{a}}\left[\mathrm{~mL} \mathrm{~g}^{-1}\right]$ & $E_{\mathrm{s}}{ }^{b}\left[\mathrm{~J} \mathrm{~g}^{-1}\right]$ & $E_{t}^{<}\left[\mathrm{J} \mathrm{g}^{-1}\right]$ & Yield $^{d}(\%)$ \\
\hline NB- $\mathrm{H}_{2} \mathrm{O}$ & 96 & 0.08 & 93 & 0.08 & 7.7 & 7.4 & 97 \\
\hline NB- $20 \mathrm{M} \mathrm{LiCl}^{6}$ & $98^{6 / 273}$ & $0.15\left(0.07 \times / 0.08^{\jmath}\right)$ & $262^{f}$ & $0.08^{f}$ & 26.5 & 21 & 73 \\
\hline NB- $20 \mathrm{M} \mathrm{LiCl}^{\mathrm{h}}$ & 273 & 0.08 & 262 & 0.08 & 21.8 & 21 & 96 \\
\hline $\mathrm{NC}-\mathrm{H}_{2} \mathrm{O}$ & $57^{6} / 51^{h}$ & $0.05^{Z} / 0.045^{h}$ & 48 & 0.045 & $2.9^{S / 2.3^{h}}$ & 2.2 & $74^{8} / 94^{h}$ \\
\hline $\mathrm{NC}-20 \mathrm{M} \mathrm{LiCl}$ & 220 & 0.08 & 198 & 0.08 & 17.6 & 15.8 & 90 \\
\hline $\mathrm{MC}-\mathrm{H}_{2} \mathrm{O}$ & 96 & 0.10 & 95 & 0.10 & 9.6 & 9.5 & 99 \\
\hline MC-20 M LiCl & 285 & 0.11 & 273 & 0.11 & 31.3 & 27.3 & 87 \\
\hline
\end{tabular}

${ }^{a}$ Intrusion ( $\left.P_{\text {int }}\right)$ and extrusion ( $\left.P_{\text {ext }}\right)$ pressure, intruded $\left(V_{\text {int }}\right)$ and extruded $\left(V_{\text {ext }}\right)$ volumes determined from intrusion-extrusion isotherms for each step. ${ }^{b}$ Stored energy $E_{s}=V_{\text {int }} \times P_{\text {int }}{ }^{c}$ Restored energy $E_{x}=V_{\text {ext }} \times P_{\text {eat }}{ }^{d}$ Energy yield $=E_{v} / E_{s} \times 100 .{ }^{c}$ First intrusion step. ${ }^{f}$ Second intrusion step. ${ }^{8}$ First cycle. ${ }^{h}$ Second and third cycles.

of 90-130 MPa, whereas only the marked step is observed for silicalite-1 microcrystals. The value of the intruded volume is slightly lower than that generally observed on microcrystals ( 0.08 against $0.10 \mathrm{~mL} \mathrm{~g}^{-1}$, respectively), which can probably be explained by the larger presence of hydrophilic defects in microporous walls which confer a hydrophilic character to a part of micropores (see the Characterization section) which are filled spontaneously. A similar effect was previously observed in the study of high pressure intrusion-extrusion in nanostructured silicalite- $1{ }^{41}$ Nevertheless, the similarity of the curves for silicalite-1 nanoboxes and microcrystals is quite remarkable. The microcrystals prepared in fluoride medium contain a small quantity of silanol defects. ${ }^{40}$ It can be expected that in spite of the synthesis and the recrystallization in hydroxide medium, the nanoboxes contain a relatively low quantity of silanol defects that is confirmed by thermogravimetric analysis and solid-state NMR measurements (see the Characterization section). Thus, the recrystallization leads to the formation of a less defective structure in comparison with the initial silicalite-1 nanocrystals.

In the case of $\mathrm{LiCl}$ aqueous solution, the intrusion-extrusion curves of initial silicalite- 1 nanocrystals are quite different from those of microcrystals. The intrusion step is extended and less pronounced and occurs in the range of $170-280 \mathrm{MPa}$ with a considerably lower intrusion pressure of $220 \mathrm{MPa}$. The intruded volume of $0.08 \mathrm{~mL} \mathrm{~g}^{-1}$ is lower than that of the microcrystals $\left(0.11 \mathrm{~mL} \mathrm{~g}^{-1}\right)$ that is typical for nanostructured silicalite-1. ${ }^{41}$ Nevertheless, both demonstrate a fully reversible spring behavior.

A drastic effect of the presence of cavities on the behavior and intrusion-extrusion characteristics is observed. In contrast to the nano- and microcrystals, the intrusion of $\mathrm{LiCl}$ aqueous solution in silicalite-1 nanoboxes is only partially reversible with the intruded volume significantly higher than that for the microcrystals in the first intrusion-extrusion cycle ( $0.15 v \mathrm{vs.}$ $0.11 \mathrm{~mL} \mathrm{~g}^{-1}$, respectively). The intrusion phase occurs in two steps.

The first one takes place continuously from the starting pressure to $220 \mathrm{MPa}$ and seems to correspond to the irreversible filling of the mesoporous cavities with an intrusion pressure of $98 \mathrm{MPa}$ and an intruded volume of $0.07 \mathrm{~mL} \mathrm{~g}^{-1}$. The second intrusion step is more pronounced and fully reversible, its intruded volume is equal to the one obtained for the water intrusion $\left(V_{\mathrm{int}}=0.08 \mathrm{~mL} \mathrm{~g}^{-1}\right)$. The intrusion pressure reaches $273 \mathrm{MPa}$ in the second intrusion step that is slightly lower than the value obtained during the intrusion of $20 \mathrm{M} \mathrm{LiCl}$ aqueous solution in silicalite-1 microcrystals $\left(P_{\text {int }}=285 \mathrm{MPa}\right) .{ }^{40}$ Thus, it corresponds probably to the reversible filling of the micropores of the hollow silicalite- 1 walls. The obtained values of intruded volume seem to be in agreement with the results of $\mathrm{N}_{2}$ adsorptiondesorption measurements (see the Characterization section). It can be supposed that the nanocavities are filled at lower pressure compared to the micropores and the filling occurs through the mesoporous cracks in the nanobox walls. These cracks become nonwetting to the concentrated $\mathrm{LiCl}$ aqueous solution contrary to water. The cracks should have very low diameter since the intrusion pressure value for the first intrusion is quite high and close to the ones obtained for large-pore zeolites. ${ }^{15}$ In order to check this hypothesis, thorough characterization of the samples has been performed.

It should be noticed that the significant increase of intruded volume in the case of $20 \mathrm{M} \mathrm{LiCl}$ aqueous solution does not lead to an improvement of energetic performance for silicalite-1 nanoboxes in comparison with that of the microcrystals The values of stored energy for the 1 st cycle are 26.5 and $31.3 \mathrm{~J} \mathrm{~g}^{-1}$, respectively. The absence of improvement is explained by the relatively low intrusion pressure of the first intrusion step ( $98 \mathrm{MPa}$ ) and the lower intruded volume of the second one ( 0.08 against $\left.0.11 \mathrm{~mL} \mathrm{~g}^{-1}\right)$. The irreversibility of the intrusion in the cavities leads to an additional decrease of stored energy in the following cycles $\left(E_{\mathrm{s}}=21.8 \mathrm{~J} \mathrm{~g}^{-1}\right)$.

\section{Transmission electron microscopy}

The crystal morphology of the samples has been examined by transmission electron microscopy (TEM). The TEM images of silicalite-1 nanocrystals before and after TPAOH treatment are presented in Fig. 2. The transformation of silicalite-1 nanocrystals (Fig. 2A) with uniform shape (ca. 100-250 nm) to the silicalite-1 nanoboxes (Fig. 2B and C) is clearly observed. The nanoboxes possess large cavities as well as regular walls of ca. 15-20 nm thickness. No crack is observed in the walls of the nanoboxes, however, it is probable that the cracks cannot be seen if they are rare and of small size. The SEM image of silicalite-1 microcrystals from the work of I. Khay et $a l^{40}$ is given for comparison (Fig. 2D).

\section{Mercury porosimetry}

The isotherms of mercury intrusion in silicalite-1 nanoboxes and nanocrystals are shown in Fig. 3. The distribution of pore size is shown in the inset of the figure. Three main mercury intrusion 


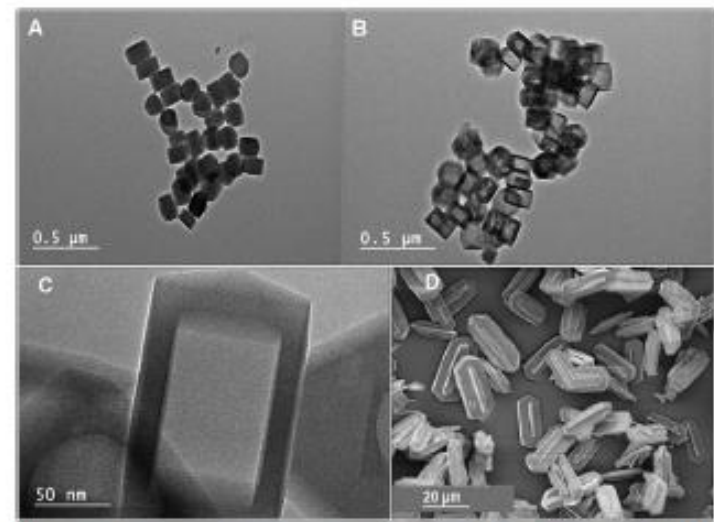

Fig. 2 Transmission electron microscopy (TEM) images of (A) the silicalite-1 nanocrystals and ( $B$ and $C$ ) the silicalite-1 nanoboxes. (D) SEM image of silicalite-1 microcrystals from ref. 40 .

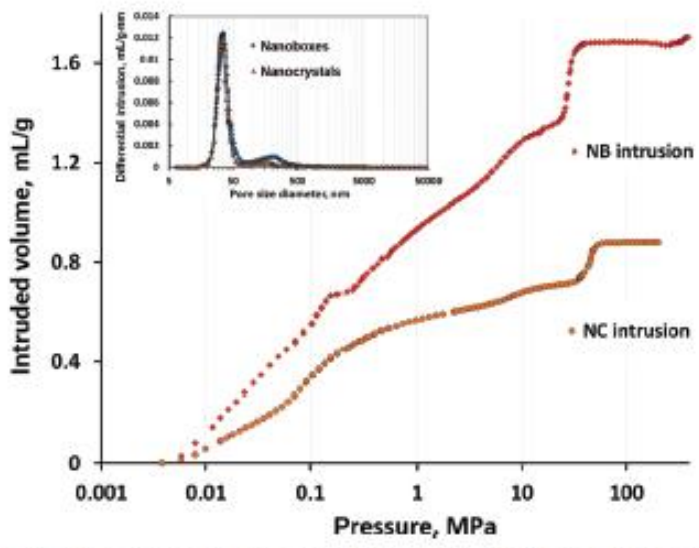

Fig. 3 Mercury porosimetry curves (intrusion) of silicalite-1 nanoboxes (NBs) and ranocrystals (NCs). The inset shows the pore size distribution.

steps are observed for both the nanocrystals and nanoboxes. The first one at a pressure lower than $1 \mathrm{MPa}$ corresponds to the compressibility of the zeolite powder. The second (between 4 and $17 \mathrm{MPa}$ ) and the third (between 20 and $60 \mathrm{MPa}$ ) intrusion steps corresponding to pore sizes of 35 and $\sim 200 \mathrm{~nm}$, respectively, are probably related to the filling of two kinds of intergranular porosity. These steps cannot be attributed to the filling of the nanobax cavities since they are observed on both the nanocrystals and nanoboxes. However, the beginning of a forth intrusion step starting at $300 \mathrm{MPa}$ is observed for the nanoboxes. This step could be related to the beginning of nanocavity filling and, thus, it could be a confirmation of the presence of small cracks in the walls of nanoboxes with a size inferior to $3 \mathrm{~nm}$, the value corresponding to the measurement limit of the porosimeter ( $400 \mathrm{MPa}$ ).

\section{X-ray diffraction}

The XRD pattems of the samples of silicalite- 1 nanocrystals and nanoboxes before and after intrusion-extrusion experiments

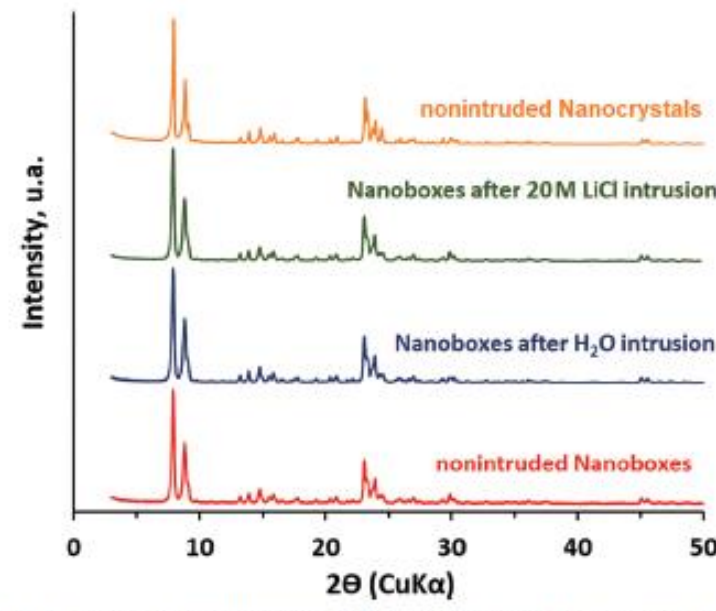

Fig. $4 \mathrm{X}$-ray diffraction patterns of the samples of silica lite- 1 manocrysta and nanoboxes before and after three intrusion-extrusion cycles in water and $20 \mathrm{M} \mathrm{LiCl}$ aqueous solution.

are reported in Fig. 4. The diffractograms, which are very alike, reveal that the intrusion-extrusion experiments do not impact the long range order of the silicalite- 1 structure. The peaks are slightly narrower and more pronounced in the case of silicalite-1 nanocrystals.

\section{Solid-state NMR spectroscopy}

The ${ }^{29}$ Si MAS NMR spectra of the nanocrystals and silicalite-1 nanoboxes before and after intrusion-extrusion experiments are shown in Fig. 5. The inset demonstrates the corresponding ${ }^{1} \mathrm{H}^{29} \mathrm{Si}$ CP MAS NMR spectra. The spectrum of the silicalite-1 nanoboxes exhibits 11 resonances in the -108 to $-118 \mathrm{ppm}$

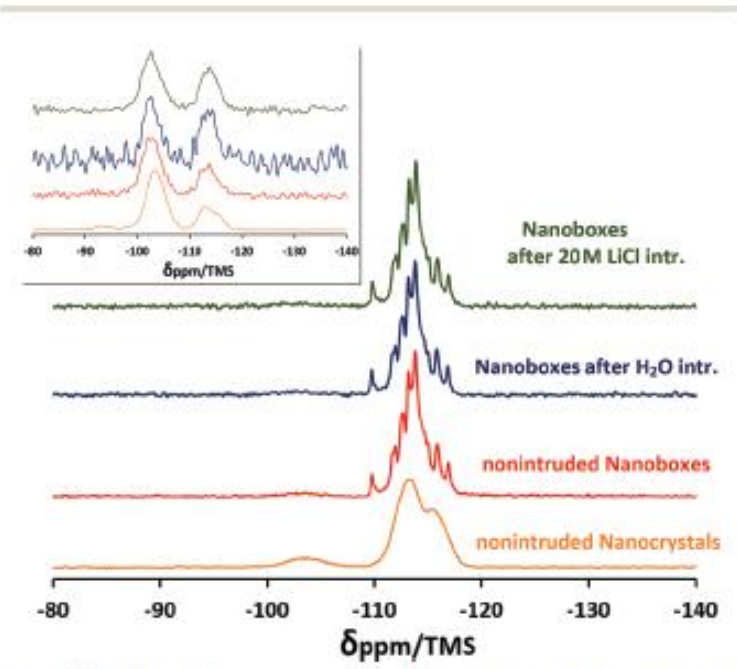

Fig. $5{ }^{29} \mathrm{Si}$ MAS NMR spectra of the samples of silicalite-1 ranocrystak and nanoboxes before and after three intrusion-extrusion cycles in water and $20 \mathrm{M} \mathrm{LiCl}$ aqueous solution. The inset shows the corresponding ${ }^{1} \mathrm{H}-{ }^{29} \mathrm{Si}$ CP MAS NMR spectra. 
range assigned to the 24 nonequivalent crystallographic silicon sites. A broad resonance of very weak intensity corresponding to $Q_{3}$ groups can also be observed at about $-103 \mathrm{ppm}$. After the intrusion-extrusion experiments, all the spectra become very similar indicating that no significant modification of the local structural order occurs in the silicalite- 1 framework of the nanoboxes. The spectrum of the nanocrystals is quite different. It exhibits only two broad resonances in the -110 to $-118 \mathrm{ppm}$ range $\left(Q_{4}\right.$ sites) indicating a lower structural order compared to the nanoboxes and one well pronounced broad resonance at $-103 \mathrm{ppm}\left(\mathrm{Q}_{3}\right.$ sites) revealing the presence of a large amount of defects. The $\mathrm{Q}_{3}$ species represent approximately $10 \%$ of the total silicon sites that corresponds to 9 silanol groups per unit cell. This value is in quite good agreement with the TGA results (see below). Thus, in comparison with the nanoboxes, the nanocrystals contain a higher number of silanol defects. This result confirms that the dissolution-recrystallization process for the nanobox formation leads to the creation of a considerably less defective framework.

The ${ }^{1} \mathrm{H}-{ }^{29} \mathrm{Si}$ CP MAS NMR spectra were performed in order to enhance the signal of silicon atoms that bear protons and thus to get evidence of the presence of silanol groups. The results confirm the conclusions mentioned above. The spectra exhibit the resonances corresponding to $\mathrm{Q}_{4}$ and $\mathrm{Q}_{3}$ sites. In the case of the nanocrystals, the resonances corresponding to $\mathrm{Q}_{2}$ species (-93.5 and $\left.-95.5 \mathrm{ppm}\right)$ are also observed. A high signal-to-noise ratio of the silicalite-1 nanocrystals, as well as a higher relative number of $Q_{2}+Q_{3}$ species, confirms that the nanocrystals contain considerably more silanol groups than the nanoboxes. Surprisingly, in the case of the nanoboxes, the relative number of $Q_{3}$ species $\left(Q_{3} / Q_{4}\right.$ ratio) is higher for the nonintruded sample than for the intruded ones that is not in agreement with other results. This could be explained by the presence of amorphous silica species in the nonintruded nanoboxes formed during the dissolution-recrystallization process and their removal from the nanoboxes by washing during the intrusion-extrusion experiments.

\section{Thermogravimetric analysis}

The experimental results of thermogravimetric (TG) analysis of silicalite-1 nanocrystals and nanoboxes before and after intrusion-extrusion experiments are depicted in Fig. 6. The total weight loss of the nonintruded nanobox sample is quite low (1.8 wt\%), but higher than that of silicalite-1 microcrystals $(\sim 0.5 \mathrm{wt} \%)^{40}$ that is probably related to the higher quantity of silanol defects. However, it is much lower than the weight loss of silicalite-1 nanocrystals ( $4.6 \mathrm{wt} \%$ ), which confirms that the nanocrystals contain more silanol defects and have more hydrophilic character which can explain low values of intruded volume due to the partial spontaneous filling of the pores. The total weight loss of the nanoboxes intruded with water is very close to that of the nonintruded nanoboxes $(2.0 \mathrm{wt} \%)$. In the case of the nanoboxes intruded with $20 \mathrm{M} \mathrm{LiCl}$ aqueous solution the total weight loss is significantly higher $(3.3 \mathrm{wt} \%)$ and this increase is mostly related to a higher quantity of physisorbed water which is desorbed at low temperature $\left(<200^{\circ} \mathrm{C}\right)$. It could

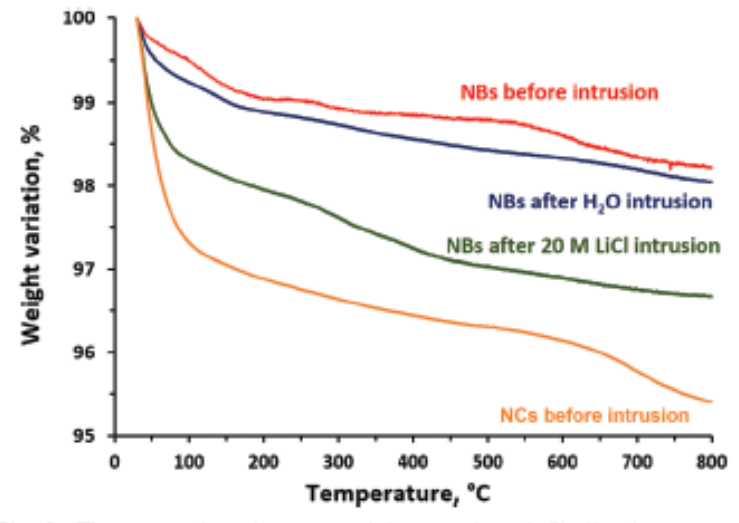

Fig. 6 Thermogravimetric curves of the samples of silicalite-1 nanocrystals (NCs) and nanoboxes (NBs) before and after three intrusion-extrusion cycles in water and $20 \mathrm{M} \mathrm{LiCl}$ aqueous solution.

be supposed that this is related to the water molecules trapped inside the mesoporous cavities after intrusion. The weight loss related to the removal of water arising from dehydroxylation reactions $\left(300-750{ }^{\circ} \mathrm{C}\right)$ comesponds to $\sim 8 \mathrm{OH}$ for the nanocrystals, $\sim 4 \mathrm{OH}$ groups per unit cell for nonintruded and water intruded nanoboxes and to $\sim 6 \mathrm{OH}$ groups for the one intruded with $20 \mathrm{M}$ Licl solution. The number of silanol groups obtained for the nanocrystals is in agreement with the results of ${ }^{29}$ Si MAS NMR 8 and 9 groups, respectively. It should be noticed that such a content of silanol defects is higher than that of silicalite-1 microcrystals $(\sim 2 \mathrm{OH}$ groups per unit cell).40

\section{$\mathrm{N}_{2}$ adsorption-desorption}

The $\mathrm{N}_{2}$ adsorption-desorption isotherms of the samples of initial silicalite-1 nanocrystals and the nanoboxes before and after three intrusion-extrusion cycles are depicted in Fig. 7. The values of BET surface area and pore volume are presented in Table 2. In the case of the nanocrystals the isotherm is mainly of type I characteristic of microporous solids with an additional clear step for high relative pressures $\left(p / p_{0}>0.9\right)$ assigned to the interparticular porosity due to the nanometric size of the crystals. The isotherms of the nanoboxes demonstrate the appearance of a $\mathrm{H} 2$ type hysteresis related to the formation of mesoporous cavities. As for the nanocrystals, the interparticular porosity is observed at high relative pressure. In the case of nanoboxes the pore size distribution determined by the BJH method on the desorption branch (average pore size: $55 \mathrm{~nm}$ ) is similar to the pore size distribution obtained by mercury porosimetry for pressures between 20 and $60 \mathrm{MPa}$ (Washburn equation, average pore size: $35 \mathrm{~nm}$ ) (Fig. 8). The latter was also assigned to an interparticular porosity.

For the nanoboxes, no significant change in pore volume is observed after intrusion-extrusion experiments. The cavity volume $\left(0.09-0.11 \mathrm{~cm}^{3} \mathrm{~g}^{-1}\right)$ is in agreement with the results of the intrusion of $20 \mathrm{M} \mathrm{LiCl}$ solution. The intruded volume corresponding to the cavity filling is lower $\left(0.07 \mathrm{~mL} \mathrm{~g}^{-1}\right)$, but it 


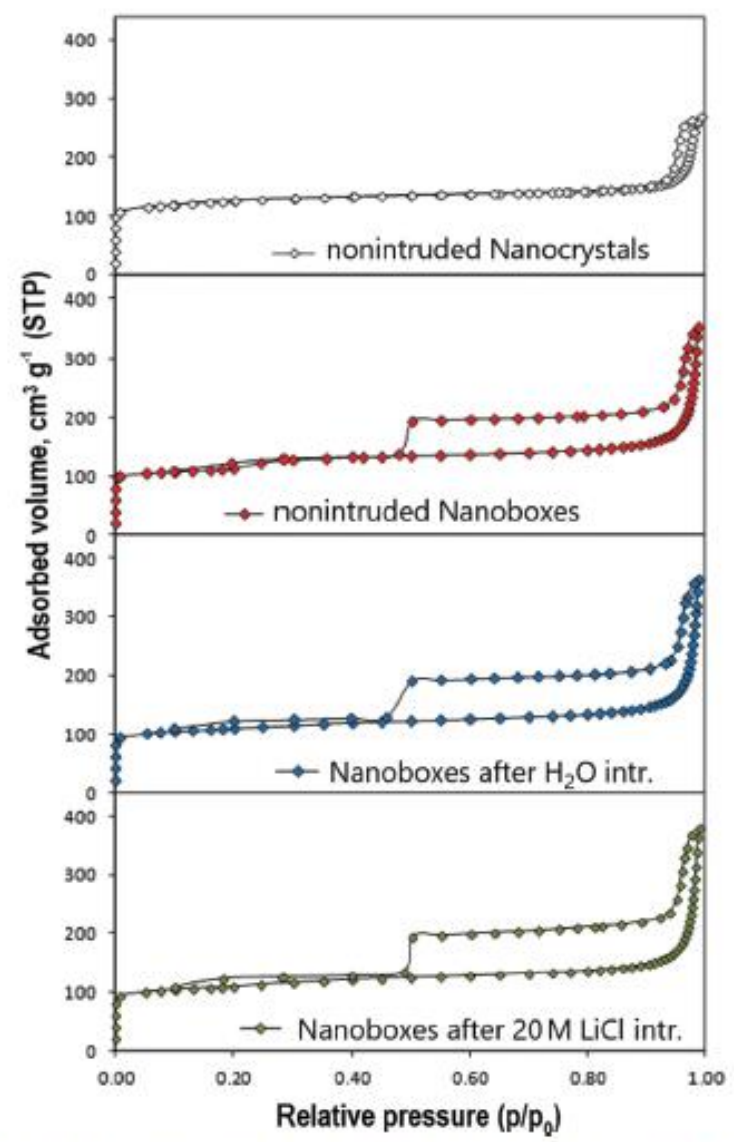

Fig. $7 \mathrm{~N}_{2}$ adsorption-desorption isotherms at $77 \mathrm{~K}$ of the samples of initial silicalite-1 nanocrystals and silicalite- 1 nanoboxes before and after three intrusion-extrusion cycles in water and $20 \mathrm{M} \mathrm{LiCl}$ aqueous solution.

Table 2 Textural properties of silicalite-1 ranocrystaks (NCs) and nanoboxes (NBs) before and after three intrusion-extrusion cycles in water and $20 \mathrm{M} \mathrm{LiCl}$ aqueous solution

\begin{tabular}{|c|c|c|c|c|}
\hline Silicalite-1 sample & $\begin{array}{l}S_{\mathrm{BFT}} \\
\left(\mathrm{m}^{2} \mathrm{~g}^{-1}\right)\end{array}$ & $\begin{array}{l}V_{\operatorname{mog}}{ }^{a} \\
\left(\mathrm{~cm}^{3} \mathrm{~g}^{-1}\right.\end{array}$ & $\begin{array}{l}V_{\text {micro }} \\
\left(\mathrm{cm}^{3} \mathrm{~g}^{-1}\right)\end{array}$ & $\begin{array}{l}V_{\operatorname{carisy}}{ }^{b} \\
\left(\mathrm{~cm}^{3} \mathrm{~g}^{-1}\right.\end{array}$ \\
\hline $\mathrm{NCs}$ & 435 & 0.41 & 0.18 & - \\
\hline NBs & 386 & 0.54 & 0.18 & 0.09 \\
\hline NBs after $\mathrm{H}_{2} \mathrm{O}$ intrusion & 360 & 0.55 & 0.16 & 0.10 \\
\hline NBs after $20 \mathrm{M} \mathrm{LiCl}$ intrusion & 356 & 0.56 & 0.16 & 0.11 \\
\hline
\end{tabular}

a The total $\mathrm{N}_{2}$ adsorbed volume $\left(V_{\text {tocal }}\right)$ was estimated at $p / p_{0}=0.99$, under such conditions the volume correspond to the sum of the microporous volume + cavity volume + interparticular volume. ${ }^{b}$ Difference in $\mathrm{N}_{2}$ uptake between the adsorption and the desorption branches of the isotherms at $p / p_{0}=0.5$.

is known that the density of intruded liquid confined in the pores is generally about $60 \%$ of the bulk one. ${ }^{44}$

\section{ICP/OES analysis}

In order to get or not evidence of the presence of lithium ions in the cavities of nanoboxes after intrusion-extrusion experiments

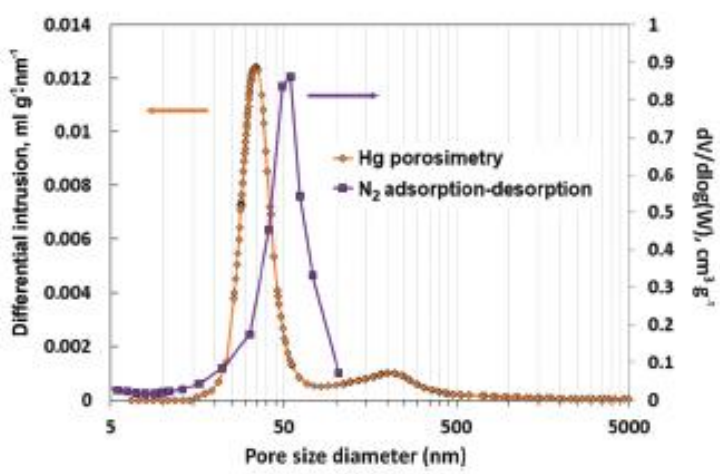

Fig. 8 Pore size distribution of silicalite -1 nanoboxes determined by the $\mathrm{BJH}$ method on the desorption branch of $\mathrm{N}_{2}$ adsorption-desorption isotherms and by mercury porosimetry.

with $20 \mathrm{M} \mathrm{LiCl}$ solution, ICP/OES analyses were performed. The results were compared to those of silicalite-1 nanocrystals. Since it is known that the intruded salt solutions can be easily removed by simple washing from the micropores, ${ }^{16}$ we perform the analysis on the samples thoroughly washed with deionized water and the unwashed ones. The washed sample of silicalite-1 nanocrystals, which demonstrated a fully reversible intrusionextrusion process, contains only $0.008 \mathrm{wt} \%$ of lithium, whereas its content in the washed nanoboxes is considerably higher $(0.25 \mathrm{wt} \%)$. Thus, the analysis confirms the presence of lithium in the cavities of nanoboxes in agreement with partially imeversible intrusion. The content of lithium in the nanoboxes is lower than the one calculated from irreversibly intruded volume of $20 \mathrm{M} \mathrm{LiCl}$ solution $(\sim 0.7 \mathrm{wt} \%)$ that can be related to partial lithium removal during the washing, probably, through the cracks in nanobox walls.

In the case of unwashed samples, the lithium content is considerably higher -1.59 and $2.40 \mathrm{wt} \%$ - for the nanocrysta ls and the nanoboxes, respectively, which can be explained by the presence of $\mathrm{LiCl}$ from the solution remaining in intergrain porosity. The difference in the lithium content between the nanoboxes and the nanocrystals $(0.81 \mathrm{wt} \%)$ fits well with the calculated one inside the cavities $(\sim 0.7 \mathrm{wt} \%)$.

\section{Experimental}

\section{Synthesis of silicalite-1 nanocrystals}

Silicalite-1 nanocrystals were prepared from a clear gel containing tetraethyl orthosilicate (TEOS, Aldrich 98\%), an alkali-free tetrapropylammonium hydroxide solution (TPAOH, $1 \mathrm{M}$ in water) and demineralized water. ${ }^{45-47}$ TPAOH was prepared by exchange of a tetrapropylammonium bromide (TPABr, Aldrich) solution with silver oxide $\left(\mathrm{Ag}_{2} \mathrm{O}\right.$, Alfa Aesar) followed by filtration in the absence of light. Typically, $19 \mathrm{~mL}$ TEOS is dispersed in $33 \mathrm{~mL}$ TPAOH under stirring. After five minutes of homogenization, $27 \mathrm{~mL}$ deminera lized water is added to the mixture and the clear gel is heated at $80{ }^{\circ} \mathrm{C}$ for 3 hours under vigorous stirring to remove the alcohol formed by hydrolysis of TEOS. The resulting solution with the following molar composition, $1 \mathrm{SiO}_{2}: 0.4 \mathrm{TPAOH}$ : $35 \mathrm{H}_{2} \mathrm{O}$, is transferred into a Teflon-lined stainless steel autoclave 
and heated in an oven at $170{ }^{\circ} \mathrm{C}$ under static conditions for 3 days. The solid is recovered by centrifugation, washed several times with distilled water until reaching a neutral $\mathrm{pH}$ and dried overnight at $90{ }^{\circ} \mathrm{C}$. The dried-solid is thereafter calcined at $550{ }^{\circ} \mathrm{C}$ in air for 6 hours to remove the organic template. Silicalite-1 nanocrystals with a uniform size of $c a$. 100 to $250 \mathrm{~nm}$ are obtained.

\section{Preparation of hollow silicalite-1 nanocrystals}

Hollow silicalite-1 nanocrystals (nanoboxes) are prepared by a dissolution-recrystallization process in the presence of TPAOH at $170{ }^{\circ} \mathrm{C}$ as previously established by Tuel et al. ${ }^{45,47} 1 \mathrm{~g}$ of the previously calcined silicalite-1 nanocrystals is dispersed in a solution containing $4.15 \mathrm{~mL} 1 \mathrm{M}$ alkali-free TPAOH and $3.32 \mathrm{~mL}$ water. The mixture is transferred to a Teflon-lined stainless steel autoclave in an oven at $170{ }^{\circ} \mathrm{C}$ for $24 \mathrm{~h}$. During this process, the highly defective core of the silicalite-1 crystal is preferentially dissolved and silica species recrystallize on the outer surface in the presence of $\mathrm{TPA}^{+}$cations ${ }^{37}$ The solid is recovered by centrifugation, washed several times with water until reaching a neutral $\mathrm{pH}$ and dried at $90{ }^{\circ} \mathrm{C}$ overnight. The dried solid is calcined at $550{ }^{\circ} \mathrm{C}$ in air to remove the TPAOH template.

\section{High-pressure intrusion-extrusion measurements}

Intrusion-extrusion of water and $20 \mathrm{M} \mathrm{LiCl}$ aqueous solution in silicalite-1 nanobox samples was performed at room temperature using a Micromeritics mercury porosimeter (Model Autopore N). Special cells with a piston containing the preliminary outgassed zeolite powder (200 $\mathrm{mg}$ in average) and the corresponding nonwetting liquid were used. The saturated Licl solution $(20 \mathrm{M})$ with a density of $1.26 \mathrm{~g} \mathrm{~mL}^{-1}$ and a surface tension of $98 \mathrm{mN} \mathrm{m}^{-148}$ was chosen because it is known to be highly effective in the improvement of HLS energetic performance due to a strong increase of intrusion pressure. ${ }^{13,15-17}$ The same device was used for mercury porosimetry measurements on nanocrystal and nanobox powders. The experimental error is estimated to be 1-2 MPa for the obtained values of pressure and $0.005-0.007 \mathrm{~mL} \mathrm{~g}^{-1}$ for those of intruded volume, thus, the error of energy values is estimated to be $7-10 \%$.

\section{Materials' characterization}

$\mathrm{X}$-ray diffraction patterns of the different samples were recorded in a Debye-Scherrer geometry on a STOE STADI-P diffractometer equipped with a curved gemanium (111) primary monochromator and a linear position-sensitive detector $\left(6^{\circ} 2 \theta\right)$ using $\mathrm{Cu} \mathrm{K} \alpha_{1}$ radiation $(\lambda=0.15406 \mathrm{~nm})$. Measurements were achieved for $2 \theta$ angle values in the $3-50^{\circ}$ range, step $0.04^{\circ}$ $2 \theta$, and time/step $=40 \mathrm{~s}$. Nitrogen adsorption-desorption isotherms were obtained at $77 \mathrm{~K}$ using a Micromeritics ASAP 2420 apparatus. Prior to the adsorption measurements, the nonintruded samples were outgassed at $300^{\circ} \mathrm{C}$ overnight under vacuum. The intruded-extruded samples were outgassed at $90{ }^{\circ} \mathrm{C}$ overnight to eliminate physisorbed water and to avoid the dehydroxylation process. The specific surface area $\left(S_{\mathrm{BET}}\right)$ and microporous volume $\left(V_{\text {micro }}\right)$ were calculated using the BET and $t$-plot methods, respectively.
Table 3 Recording conditions of the ${ }^{29} \mathrm{Si}$ MAS and ${ }^{1} \mathrm{H}-{ }^{29} \mathrm{Si}$ CPMAS NMR spectra

\begin{tabular}{lll}
\hline & ${ }^{29} \mathrm{Si}$ MAS & ${ }^{1} \mathrm{H}^{29} \mathrm{Si}$ CPMAS \\
\hline Chemical shift standard & $\mathrm{TMS}^{2}$ & $\mathrm{TMS}^{2}$ \\
Frequency $(\mathrm{MHz})$ & 59.6 & 59.6 \\
Pulse width $(\mu \mathrm{s})$ & 2.60 & 5.00 \\
Flip angle & $\pi / 6$ & $\pi / 2$ \\
Contact time $(\mathrm{ms})$ & - & 8 \\
Recycle time $(\mathrm{s})$ & 80 & 6 \\
Spinning rate $(\mathrm{kHz})$ & 4 & 4 \\
Scan number & 1500 & 20000
\end{tabular}

${ }^{a}$ Tetramethylsilane. ${ }^{b}$ The relaxation time $t_{1}$ was optimized.

Thermogravimetric (TG) analyses were carried out on a Mettler Toledo STARe apparatus, under air flow, with a heating rate of $5{ }^{\circ} \mathrm{C} \mathrm{min}-1$ from 30 to $800{ }^{\circ} \mathrm{C}$.

The morphology, homogeneity and particle sizes of the synthesized materials were investigated using a transmission electron microscope (TEM) JEOL model ARM-200F, at an acceleration voltage of $200 \mathrm{kV}$, with a point-to-point resolution of $80 \mathrm{pm}$.

Measurements by Inductively Coupled Plasma Optical Emission Spectroscopy (ICPOES) were carried out using a Thermo Model 6300DUO spectrometer in order to determine the presence of lithium atoms in the pores of zeolites after intrusion-extrusion experiments. The lithium concentration was determined after dissolution of samples in $\mathrm{HF}$, neutralization by $\mathrm{H}_{3} \mathrm{BO}_{3}$, filtration and dilution up to $50 \mathrm{~mL}$ with ultra-pure water. The wavelength of the corresponding spectrometric lines that were used for the analysis was Li: $670.784 \mathrm{~nm}$.

The NMR spectra were recorded at room temperature on a Bruker Advance II $300 \mathrm{MHz}$ spectrometer, with a doublechannel $7 \mathrm{~mm}$ Bruker MAS probe. The recording conditions are given in Table 3.

\section{Conclusions}

The study of high pressure intrusion-extrusion of water and $20 \mathrm{M} \mathrm{LiCl}$ solution in silicalite-1 nanoboxes (hollow nanocrystals) obtained by nanocrystal dissolution-recrystallization has been performed. It demonstrates how the nanostructure can determine the properties of materials. The drastic effect of the presence of cavities on the behavior and intrusion-extrusion characteristics has been observed, particularly, in the case of $\mathrm{LiCl}$ aqueous solution. In contrast to the spring behavior of silicalite-1 micro- and nanocrystals, the nanoboxes demonstrate a combination of bumper and spring behavior in the first intrusion-extrusion cycle. The intrusion of $20 \mathrm{M} \mathrm{Licl}$ solution is only partially reversible and takes place in two clearly marked steps. The first one with an intruded volume of $0.07 \mathrm{~mL} \mathrm{~g}^{-1}$ and an intruded pressure of $98 \mathrm{MPa}$ is irreversible and corresponds probably to the filling of mesoporous cavities, whereas the second one with an intruded volume of $0.08 \mathrm{~mL} \mathrm{~g}^{-1}$ and an intrusion pressure of $273 \mathrm{MPa}$ is fully reversible and related to the filling of the hydrophobic micropores of silicalite-1 walls. Thus, the total intruded volume is significantly higher than the ones obtained for the microcrystals and the nanocrystals 
( 0.15 vs 0.10 and $0.08 \mathrm{~mL} \mathrm{~g}^{-1}$, respectively). It can be supposed that the filling of the cavity occurs through small mesoporous cracks in the walls of nanoboxes. The results of mercury porosimetry seem to confim this hypothesis. In the case of water intrusion, no significant change in intrusion-extrusion curves is observed compared to silicalite-1 microcrystals. The mesoporous cavities are probably filled spontaneously with water and only the intrusionextrusion process in the microporous walls takes place at high pressure. The characterization by structural and physicochemica methods shows that the dissolution-recrystallization process leads to the formation of a zeolite framework with considerably lower content of silanol groups in comparison with the initial nanocrystals and no significant impact of intrusion-extrusion experiments on the silicalite-1 nanobox structure.

Unfortunately, the significant increase of the intruded volume does not lead to energetic performance improvement for silicalite-1 nanoboxes in comparison with the microcrystals (stored energy of 26.5 and $31.3 \mathrm{~J} \mathrm{~g}^{-1}$, respectively, in the 1 st cycle), because of the relatively low intrusion pressure ( $96 \mathrm{MPa}$ ) of the first intrusion step and the lower intruded volume of the second one ( 0.08 against $0.11 \mathrm{~mL} \mathrm{~g}^{-1}$ ). The irreversibility of the intrusion in the cavities leads to an additional decrease of stored energy in the following cycles.

\section{Conflicts of interest}

There are no conflicts to declare in this manuscript.

\section{References}

1 V. Eroshenko, Int. Pat., WO96/18040, 1996.

2 V. Eroshenko, URSS Pat., 1333870, 1985.

3 V. A. Eroshenko, presented at MMT-2014 Conference, Ariel, Israel, July 2014, vol. 2, pp. 4-212.

4 V. Eroshenko and A. Fadeev, Colloid J., 1995, 57, 446.

5 A. Y. Fadeev and V. Eroshenko, J. Colloid Interface Sci., 1997, $187,275$.

6 V. Eroshenko, R. C. Regis, M. Soulard and J. Patarin, J. Am. Chem. Soc., 2000, 123, 8129.

7 L. Tzanis, M. Trzpit, M. Sou lard and J. Patarin, J. Phys. Chem. C, 2012, 116, 20389.

8 O. V. Ievtushenko, V. A. Eroshenko, Y. G. Grosu, J.-M. Nedelec and J.-P. Grolier, Phys Chem. Chem. Phys., 2013, 15, 4451.

9 G. Fraux, F.X. Coudert, A. Boutin and A. Fuchs, Chem. Soc. Rev., 2017, 46, 7421.

10 L. Tzanis, M. Trzpit, M. Soulard and J. Patarin, Microporous Mesoporous Mater., 2011, 146, 119.

11 L. Tzanis, M. Trzpit, M. Soulard and J. Patarin, J. Phys. Chem. C, 2012, 116, 4802.

12 L. Tzanis, B. Marler, H. Gies and J. Patarin, J. Phys. Chem. C, 2013, 117, 4098.

13 A. Ryzhikov, L. Ronchi, H. Nouali, T. J. Daou, J.-L. Paillaud and J. Patarin, J. Phys. Chem. C, 2015, 119, 28319.

14 A. Ryzhikov, I. Khay, H. Nouali, T. J. Daou and J. Patarin, RSC Adv., 2014, 4, 37655.

43 I. Batonneau-Gener and A. Sachse, J. Phys. Chem. C, 2019, 123,4235 .

44 N. Desbiens, I. Demachy, A. H. Fuchs, H. Kirsch-Rodeschini, M. Soulard and J. Patarin, Angew. Chem., Int. Ed., 2005, 44, 5310.

45 Y. Wang, M. Lin and A. Tuel, Microporous Mesoporous Mater., 2007, 102, 80.
15 L. Ronchi, A. Ryzhikov, H. Nouali, T. J. Daou and J. Patarin, Microporous Mesoporous Mater., 2018, 255, 211.

16 A. Ryzhikov, I. Khay, H. Nouali, T. J. Daou and J. Patarin, Phys Chem. Chem. Phys., 2014, 16, 17893.

17 L. Ronchi, A. Ryzhikov, H. Nouali, T. J. Daou and J. Patarin, J. Phys Chem. C, 2018, 122, 2726.

18 G. Ortiz, H. Nouali, C. Marichal, G. Chaplais and J. Patarin, Phys Chem. Chem. Phys., 2013, 15, 4888.

19 Y. Grosu, M. Li, Y.-L. Peng, D. Luo, D. Li, A. Faik, J.-M. Nedelec and J.-P. Grolier, ChemPhysChem, 2016, 17, 3359.

20 I. Khay, G. Chaplais, H. Nouali, C. Marichal and J. Patarin, RSC Adv., 2015, 5, 31514.

21 M. Michelin-Jamois, C. Picard, G. Vigier and E. Charlaix, Phys Rev. Lett., 2015, 115, 036101.

22 G. Ortiz, H. Nouali, C. Marichal, G. Chaplais and J. Patarin, J. Phys Chem. C, 2014, 118, 7321.

23 T. Martin, B. Lefevre, D. Brunel, A. Galameau, F. Di Renzo, F. Fajula, P. F. Gobin, J. F. Quinson and G. Vigier, Chem. Commun, 2002, 24.

24 B. Lefevre, A. Saugey, J.-L. Barrat, L. Bocquet, E. Charlaix, P.-F. Gobin and G. Vigier, Colloids Surf., A, 2004, 241, 265.

25 L. Guillemot, A. Galarneau, G. Vigier, T. Abensur and E. Charlaix, Rev. Sci. Instrum., 2012, 83, 105105.

26 A. Han and Y. Qiao, Chem. Phys. Lett., 2008, 454, 294.

27 A. Han, W. Lu, V. K. Punyamurtula, T. Kim and Y. Qiao, J. Appl Phys, 2009, 105, 024309.

28 A. Han, X. Kong and Y. Qiao, J. Appl. Phys, 2006, 100, 014308.

29 A. Ryzhikov, I. Khay, H. Nouali, T. J. Daou and J. Patarin, Microporous Mesoporous Mater., 2016, 221, 1.

30 M. Choi, K. Na, J. Kim, Y. Sakamoto, O. Terasaki and R. Ryoo, Nature, 2009, 461, 246.

31 A. Astafan, M. A. Benghalem, Y. Pouilloux, J. Patarin, N. Bats, C. Bouchy, T. J. Daou and L. Pinard, J. Catal, 2016, 336, 1.

32 I. Kabalan, B. Lebeau, H. Nouali, J. Toufaily, T. Hamieh, B. Koubaissy, J.-P. Bellat and T. J. Daou, J. Phys. Chem. C, 2016, 120, 2688.

33 L. El Hanache, B. Lebeau, H. Nouali, J. Toufaily, T. Hamieh and T. J. Daou, J. Hazard. Mater., 2019, 364, 206.

34 M. Trzpit, M. Soulard and J. Patarin, Microporous Mesoporous Mater., 2009, 117, 627.

35 M. Trzpit, M. Soulard and J. Patarin, J. Mater. Sci, 2009, 44, 6525 .

36 D. Farrusseng and A. Tuel, New J. Chem., 2016, 40, 3933.

37 C. Pagis, A. R. Morgado Prates, D. Farrusseng, N. Bats and A. Tuel, Chem. Mater., 2016, 28, 5205.

38 D. Laprune, A. Tuel, D. Farrusseng and F. Meunier, AppL Catal., A, 2017, 535, 69.

39 S. Li, A. Tuel, D. Laprune, F. Meunier and D. Farrusseng, Chem. Mater., 2015, 27, 276.

40 I. Khay, T. J. Daou, H. Nouali, A. Ryzhikov, S. Rigolet and J. Patarin, J. Phys. Chem. C, 2014, 118, 3935.

41 I. Kabalan, I. Khay, H. Nouali, A. Ryzhikov, B. Lebeau, S. Albrecht, S. Rigolet, M.-B. Fadlallah, J. Toufaily and T. Hamiyeh, et al., J. Phys. Chem. C, 2015, 119, 18074.

42 C. Pagis, PhD thesis, Université de Lyon, 2018.

46 L. Burel and A. Tuel, Microporous Mesoporous Mater., 2013, 174, 90 .

47 Y. Wang and A. Tuel, Microporous Mesoporous Mater., 2008, $113,286$.

48 P. Wang, A. Anderko and R. D. Young, Ind. Eng. Chem. Res., 2011, 50, 4086. 